\title{
Initial Study for Cerium and Lanthanum Extraction from Bangka Tin Slag through $\mathrm{NaOH}$ and $\mathrm{HClO}_{4}$ Leaching
}

\author{
Badrul Munir ${ }^{{ }^{*}}$, Sulaksana Permana ${ }^{*}$, Anggita Amilia $^{1}$, Ahmad Maksum ${ }^{1,2}$ and Johny W Soedarsono ${ }^{1}$, \\ ${ }^{1}$ Department of Metallurgy and Materials Engineering, Universitas Indonesia, 16424 Depok, Indonesia \\ ${ }^{2}$ Mechanical Engineering Department, Politeknik Negeri Jakarta, Depok 16425, Indonesia
}

\begin{abstract}
The global demand for rare earth elements have increased dramatically for the last decade as more and more devices use rare earth elements as key for their advanced properties. The paper explores the possibilty to recover cerium (Ce) and lanthanum (La) in Bangka tin slag (BTS) involving roasting at $900^{\circ} \mathrm{C}$, water-quenching, and two leachings, $8 \mathrm{M} \mathrm{NaOH}$ leaching and $\mathrm{HClO}_{4}$ leaching at concentrations of $0.1 \mathrm{M}, 0.4 \mathrm{M}$, and $0.8 \mathrm{M}$. $\mathrm{HClO}_{4}$ leaching causes $\mathrm{Ce}$ and $\mathrm{La}$ contents to decrease to $0.47 \%$ for $0.1 \mathrm{M}, 0.51 \%$ for $0.4 \mathrm{M}$, and $0.59 \%$ for $0.8 \mathrm{M}$. On the other hand, $8 \mathrm{M} \mathrm{NaOH}$ optimizes cerium and lanthanum contents up to $4.35 \%$ and $1.45 \%$, respectively.
\end{abstract}

\section{Introduction}

Several studies showed that metallurgical processes can be applied to extract precious metals from slag as a secondary source [1-4]. Meanwhile, other investigations expose the benefits of using non-fluoride acids to enrich valuable metals contents in slag which are environmentally friendly to the environment [5-7]. Rare Earth (RE) elements are found primarily in the ore of aluminum, copper, zinc, and nickel. The use of RE keeps increasing every year and there is little alternative or substitute materials in term of properties resulting in continous soaring price every year. Therefore, the role of recycling is essential for RE acquisition and supply [8]. To overcome the difficulty of recycling $\mathrm{RE}$ from secondary sources, further exploration of processing RE cannot be ignored [9].

On the other hand, China domination in RE mining and processing as well as the decision to impose restrictions on $\mathrm{rE}$ export has the prices soar dramatically in 2011 [10].

In spite of all the situation concerning invaluable metals above, Indonesia may not be worried because the massive tin mining waste generated during the mining process and the post-processing slag in the BangkaBelitung Islands has the potential to be a huge source for the supply of critical metals [2].

Tin slag is a byproduct of tin smelting. In this regard, Bangka tin slag (BTS) 1 contains 20 30\% Sn while BTS 2 has a 2 3\% Sn contents [11]. One tin smelter in the Bangka-Belitung archipelago, Indonesia, has a very large tin slag output [12]. Several previous studies confirmed that tin slag contains $\mathrm{Ta}$ and $\mathrm{Nb}[4,13$, 14, 16], $\mathrm{U}$ and Th [17, 18], and RE [2].
Several investigations involving the processing of critical metals are presented hereafter. The kinetics and mechanism of ammonium sulphate leaching in RE indicates the higher the leaching temperature or the smaller the particle size of the ore, the faster the leaching progress [19].

Furthermore, the solubility of RE and yttrium phosphate in aqueous solution is highly dependent on the condition of solid phase formation. Compared to the slowly formed, well-aged, and coarse precipitates, fresh sediment is much easier to dissolve. The patterns of solubility products of RE and yttrium phosphate are generally similar to the fractionation patterns which developed during phosphate coprecipitation [20]. The evaluation of chloride formation constants and fluoridespecies aqua bearing from all RE III groups at temperatures up to $300^{\circ} \mathrm{C}$ shows that the elevated temperature of $\mathrm{LREF}^{2+}$ species is more stable than HREF $^{2+}$ species (this fact is contrary to the theoretical prediction) [21].

Next, a novel approach to characterize and extract critical metals based on hydro and pyrometallurgy has been applied to tin slag. In this research, subsequent alkaline plannings and slag's acid washing based on the pseudo-structure of amorphous materials result in (1) the selective dissolution of critical metals, (2) the low consumption of chemical reagents, mainly HF, (3) less toxic residues, and (4) high grade concentrates production, up to $60 \%$ of tantalum and niobium pentoxides with a satisfactory recovery rate about $85 \%$. These concentrates, then, undergo selective carbon chlorination at temperatures of less than $500^{\circ} \mathrm{C}$, which leads to the full extraction of niobium at $300^{\circ} \mathrm{C}$ and tantalum at $500^{\circ} \mathrm{C}[15]$.

The separation of radioactive elements and rare earth elements from BTS engages several processes. First, BTS undergoes base smelting at $700^{\circ} \mathrm{C}$ with 
$\mathrm{NaOH}$. This process produces silica free hydroxide cake. Furthermore, the BTS is $\mathrm{H}_{2} \mathrm{SO}_{4}$-leached and undergoes precipitation with $\mathrm{H}_{2} \mathrm{SO}_{4}$ followed by the addition of $\mathrm{NH}_{4} \mathrm{OH}$. Hydroxide cake leaching and $\mathrm{H}_{2} \mathrm{SO}_{4}$ leaching aims at separating the radioactive elements and rare earth elements from BTS. The results are $\mathrm{NaRE}\left(\mathrm{SO}_{4}\right)_{2}$ sludge and uranium-thorium sulfate solution: $27.01 \%$ uranium, $61.67 \%$ thorium, and $1 \%$ rare earth elements. Other results are $\mathrm{Th}\left(\mathrm{C}_{2} \mathrm{O}_{4}\right)_{2}$ sludge and $\mathrm{UO}_{2} \mathrm{C}_{2} \mathrm{O}_{4}$ solution [3].

This investigation aims at recovering cerium and lanthanum contents in BTS. The recovery processes are comprised of $8 \mathrm{M} \mathrm{NaOH}$ leaching followed by $\mathrm{HClO}_{4}$ at concentrations of $0.1 \mathrm{M}, 0.4 \mathrm{M}$, and $0.8 \mathrm{M}$. From both leachings, $8 \mathrm{M} \mathrm{NaOH}$ leaching has proven to be able to enhance cerium and lanthanum contents.

\section{Methodology}

\subsection{Materials and Apparatus}

The investigated tin slag was taken from a tin smelter in the Bangka-Belitung archipelago, Indonesia. Bangka tin slag is shortened to BTS. The leaching solutions include technical sodium hydroxide and perchloric acid (p.a). The research tools consist of a Barnstead Thermolyne Furnace, a ceramic container, a ball mill (Toptek Topvert G1), a sieve, a magnetic stirrer (Thermo Scientific CIMAREC), and characterization tools: an X-Ray Flourence (XRF) Bruker handheld XRF analyzer and an Atomic Absorption Spectroscopy (AAS) PerkinElmer Analyst 400 .

\subsection{Research Procedure}

The first step was the characterization of BTS using XRF. Next, BTS was roasted, water-quenched, and sieved. These three processes are abbreviated as RQS. After that, BTS-RQS with a size of $-200+250$ mesh which was to be further processed was measured with a ratio of $1: 10$. Based on this comparison, the researchers used $90 \mathrm{~mL}$ equal to 176 grams of tin slag as samples and $900 \mathrm{~mL}$ of $8 \mathrm{M} \mathrm{NaMH}$ solution. Then, the sample was leached with $8 \mathrm{M} \mathrm{NaOH}$ for 2 hours at a room temperature of $25^{\circ} \mathrm{C}$. After leaching, the residues and filtrates were separated by a filtering paper. The residues were then washed with aquadest to remove the residual $\mathrm{NaOH}$ solution. After washing, the residues were dewatered through an oven at $100^{\circ} \mathrm{C}$ for 2 hours. Furthermore, the residues from $\mathrm{NaOH}$ leaching and the residues from $\mathrm{HClO}_{4}$ leaching were characterized by XRF. Meanwhile, the filtrates characterization used AAS After undergoing $8 \mathrm{M} \mathrm{NaOH}$ leaching, the sample was then leached with $\mathrm{HClO}_{4}$ at concentrations of $0.1 \mathrm{M}$, $0.4 \mathrm{M}$, and $0.8 \mathrm{M}$. The sample of $\mathrm{HClO}_{4}$ leaching was the residues from $\mathrm{NaOH}$ leaching. Similar to alkaline leaching $(\mathrm{NaOH})$, the ratio between the sample and leaching solution in $\mathrm{HClO}_{4}$ leaching is $1: 10$. Therefore, the researchers used $30 \mathrm{~mL}$ (50 grams) of tin slag and $300 \mathrm{~mL}$ of $\mathrm{HClO}_{4}$ solution. The leaching process took 2 hours at a room temperature of $25^{\circ} \mathrm{C}$. The residues and filtrates of this leaching were then separated by a filtering paper. The residues were then washed with aquadest to remove the residual $\mathrm{HClO}_{4}$ solution. After washing, the residues were dewatered thorugh an oven at $100^{\circ} \mathrm{C}$ for 2 hours. Thereafter, 8 grams of the residues from $\mathrm{HClO}_{4}$ leaching were characterized by XRF while the filtrates characterization used AAS. Fig. 1 shows the details of research procedure.

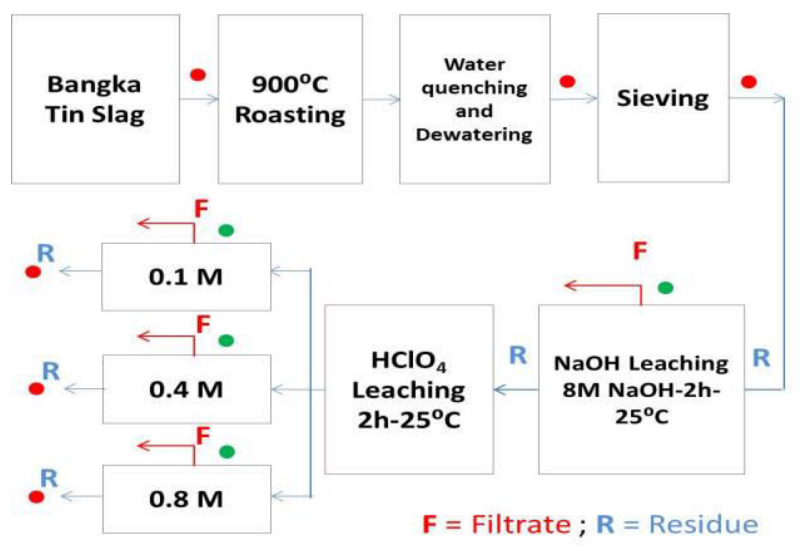

Characterization : (๑) XRF (๑) AAS

Fig. 1. Research procedure.

\section{Results and Discussion}

This chapter covers several sub-chapters, including (1) BTS characterization, (2) roasting, water-quenching, and sieving of BTS, (3) $\mathrm{NaOH}$ leaching of BTS-RQS, and (4) $\mathrm{HClO}_{4}$ leaching of the residues from $\mathrm{NaOH}$ leaching.

All elements and oxides in BTS are divided into 3 groups. The first group consists of two valuable oxides to be recovered, cerium (Ce) and lanthanum (La). The second one is major other oxides (MOO) that include $\mathrm{SiO}_{2}, \mathrm{TiO}_{2}, \mathrm{Fe}_{2} \mathrm{O}_{3}, \mathrm{CaO}, \mathrm{Al}_{2} \mathrm{O}_{3}, \mathrm{Zr}$, and $\mathrm{Sn}$. The last one is comprised of elements and minor oxides (EMO) consisting of $\mathrm{P}_{2} \mathrm{O}_{5}, \mathrm{Y}, \mathrm{Bi}, \mathrm{MnO}, \mathrm{Nb}, \mathrm{Ta}, \mathrm{Th}, \mathrm{MnO}, \mathrm{V}$, $\mathrm{Cr}, \mathrm{W}, \mathrm{U}, \mathrm{Ni}, \mathrm{Hf}, \mathrm{Se}, \mathrm{K}_{2} \mathrm{O}$, and $\mathrm{Ag}$.

\subsection{BTS Characterization}

The initial characterization of BTS shows cerium and lanthanum contents, $1.57 \%$ and $0.13 \%$, respectively. The cerium contents are high compared to those in other studies, which have only $0.120 \% \quad \mathrm{Ce}_{2} \mathrm{O}_{3}$ [22]. The process of recovering $\mathrm{Ce}$ and $\mathrm{La}$ contents in this study was carried out through dissolving other oxides. Similar processes were also applied to previous dissolution studies, where red mud (wasted raw material in industrial alumina) was dissolved to recover $\mathrm{Fe}, \mathrm{Al}, \mathrm{Ti}$, and $\mathrm{Si}$ [23]. Table 1 shows the details of cerium and lanthanum contents in Bangka tin slag.

Table 1. The results of XRF characterization of BTS.

\begin{tabular}{lcccccc}
\hline Element & $\mathbf{C e}$ & $\mathbf{L a}$ & $\mathbf{T i O}_{2}$ & $\mathbf{Z r}$ & Sn & EMO \\
\hline $\begin{array}{l}\text { Content } \\
(\%)\end{array}$ & 1.57 & 0.13 & 2.38 & 1.33 & 1.78 & 82.15 \\
\hline
\end{tabular}




\subsection{Roasting, Water-Quenching, and Sieving of BTS}

As informed in a prior research, the roasting of tin slag causes anisotropy thermal expansion while waterqueching produces a broken strain and residual stress. Based on the grain size of tin slag, the size of the residual stress is so high that this stress creates micro cracks in tin slag [24]. Tin slag itself has an amorphous structure. This structure is always broken before deformation occurs at a room temperature. The magnitude of the fracture strength is relatively smaller than the theory of interatomic bonding. The smaller fracture strength than the interatomic bonding theory is caused by a minor defect in tin slag that can increase the stress. The rise in the stress is signified by micro cracks, internal pores, and the grain angles difficult to control [25]. Through amorphous materials, roasting, and waterquenching, oxides having weak a interatomic bonding force become easily pulled from oxides having a strong interatomic bonding force. As the processes above, cerium oxide and lanthanum in this exploration were extracted from $\mathrm{MOO}$ and EMO.

$900^{\circ} \mathrm{C}$ roasting and water-quenching of BTS yielded various contents of $\mathrm{Ce}+\mathrm{La}$ in each particle size. In association with this finding, roasting and water quenching in previous investigations has the same effect on the contents of each grain size of BTS $[11,26]$.

Differences in contents in each grain size of BTS were not only present in valuable oxides, but also in MOO and EMO. Ce + La contents in BTS that have not been processed at all amounted to $1.70 \%$. However, after undergoing several processes, namely roasting, waterquenching, and sieving, the lowest $\mathrm{Ce}+\mathrm{La}$ contents in the BTS were $1.25 \%$ present in -250 mesh BTS particles while the highest ones were $5.03 \%$ present in $-200+250$ mesh BTS particles. Since the $-200+250$ mesh BTSRQS particles had the highest contents of $\mathrm{Ce}+\mathrm{La}$ but low contents of EMO, the BTS-RQS particles of that size were used as samples in $\mathrm{NaOH}$ leaching. Table 2 shows the contents of elements and oxides in both BTS and BTS-RQS.

\section{3. $\mathrm{NaOH}$ Leaching of BTS-RQS}

To see the condition of ions or compounds in the leaching process, the researchers used the Ellingham diagram. In general, the ionic conditions of a chemical element in the Ellingham diagram indicate that the chemical element will dissolve while the conditions of the compound indicate that the element is insoluble. Evaluation through the Ellingham diagram requires a $\mathrm{pH}$ value of the solution. In this regard, the $\mathrm{pH}$ value of the $8 \mathrm{M} \mathrm{NaOH}$ solution was calculated using the formula $\mathrm{pOH}=-\log \mathrm{C}_{\mathrm{OH}}{ }^{-}$and $\mathrm{pH}+\mathrm{pOH}=14$. These calculations yielded a $\mathrm{pH}$ value of 14,903 .

The results of $8 \mathrm{M} \mathrm{NaOH}$ leaching in BTS-RQS are provided in Table 3. This table shows $5.8 \% \mathrm{Ce}+\mathrm{La}$, $36.48 \% \mathrm{MOO}$, and $57.72 \%$ EMO. Meanwhile, the overall comparison between the $\mathrm{Ce}+\mathrm{La}, \mathrm{MOO}$, and EMO contents present in the BTS and those present in the BTS-RQS residues after $8 \mathrm{M} \mathrm{NaOH}$ leaching is on Fig.2.

Table 2. The contents of elements and oxides in both BTS and BTS-RQS

\begin{tabular}{|l|c|c|c|c|c|c|}
\hline \multirow{2}{*}{$\begin{array}{c}\text { Eleme- } \\
\text { nts }\end{array}$} & \multirow{2}{*}{$\begin{array}{c}\text { Content } \\
(\%)\end{array}$} & \multicolumn{6}{|c|}{ Content of BTS-RQS (\%) at each } \\
\cline { 3 - 7 } & & 100 & $\begin{array}{c}100- \\
150\end{array}$ & $\begin{array}{c}150- \\
200\end{array}$ & $\begin{array}{c}200- \\
250\end{array}$ & 250 \\
\hline $\mathrm{Ce}$ & 1.57 & 3.99 & 3.54 & 1.27 & 3.93 & 1.01 \\
\hline $\mathrm{La}$ & 0.13 & 0.68 & 0.60 & 0.26 & 1.10 & 0.24 \\
\hline $\mathrm{SiO}_{2}$ & 6.56 & 14.4 & 15.6 & 4.68 & 12.89 & 4.75 \\
\hline $\mathrm{TiO}_{2}$ & 2.38 & 6.29 & 6.75 & 1.82 & 3.32 & 1,78 \\
\hline $\mathrm{Fe}_{2} \mathrm{O}_{3}$ & 2.36 & 6.17 & 6.60 & 2.01 & 4.17 & 1.97 \\
\hline $\mathrm{CaO}$ & 1.22 & 5.22 & 5.69 & 0.03 & 4.42 & - \\
\hline $\mathrm{Al}_{2} \mathrm{O}_{3}$ & 0.52 & 2.93 & 3.28 & 0.24 & 2.96 & - \\
\hline $\mathrm{Zr}$ & 1.33 & 4.65 & 4.52 & 1.52 & 4.05 & 1.55 \\
\hline $\mathrm{Sn}$ & 1.78 & 6.04 & 6.39 & 2.63 & 7.06 & 2.93 \\
\hline $\mathrm{EMO}$ & 82.2 & 49.6 & 47.0 & 90.2 & 56.1 & 85.8 \\
\hline
\end{tabular}

Table 3. The results of characterization of residues from $\mathrm{NaOH}$ leaching.

\begin{tabular}{lcccccc}
\hline Element & $\mathbf{C e}$ & $\mathbf{L a}$ & $\mathbf{T i O}_{2}$ & $\mathbf{Z r}$ & $\mathbf{S n}$ & EMO \\
\hline $\begin{array}{l}\text { Residue } \\
(\%)^{1}\end{array}$ & 4.35 & 1.45 & 3.23 & 4.07 & 6.49 & 57.72 \\
$\begin{array}{l}\text { Filtrate } \\
(\mathrm{ppm})^{2}\end{array}$ & - & - & - & - & - & - \\
\hline
\end{tabular}

${ }^{1}$ XRF characterization ${ }^{2}$ AAS characterization

On Fig.3 (a), the rise in $\mathrm{Ce}+\mathrm{La}$ contents show that at $\mathrm{pH} 14.903$, cerium is more dominant in the form of $\mathrm{CeH}_{2}$ and $\mathrm{CeO}_{2}$. This means that $8 \mathrm{M} \mathrm{NaOH}$ leaching only dissolves little cerium. On the other hand, the dominant lanthanum is in the form of $\mathrm{LaH}_{2}$ and $\mathrm{La}(\mathrm{OH})_{3}$, as shown on Fig. 3 (b). This implies that $8 \mathrm{M}$ $\mathrm{NaOH}$ leaching does not dissolve lanthanum. Of these two leachings, the most influential on enhancing $\mathrm{Ce}+\mathrm{La}$ contents is the dissolution of $\mathrm{MOO}$ during $\mathrm{NaOH}$ leaching, as shown on Fig. 2 where the extreme decrease occurred in MOO contents, from $82.15 \%$ to $57.72 \%$.

The results of AAS characterization of MOO: Fe and $\mathrm{Ca}$ (Table 3) show Fe $2 \mathrm{ppm}$ and non-detected Ca. That means that $\mathrm{NaOH}$ leaching slightly dissolves $\mathrm{Fe}$ and $\mathrm{Ca}$.

Fig. 2 shows the increase in all MOO oxides contents. Nevertheless, this rise is not due to the dissolution of MOO. Chronologically, based on the negative value of Gibbs free energy $(\Delta G)$ in Table 4, the reactions of $\mathrm{MOO}$ to $\mathrm{NaOH}$ leaching indicated dissolution. It was signified by a spontaneous reaction. Thus, it concludes that the increase in MOO contents is due to the dissolution of large-scale EMO contents. 


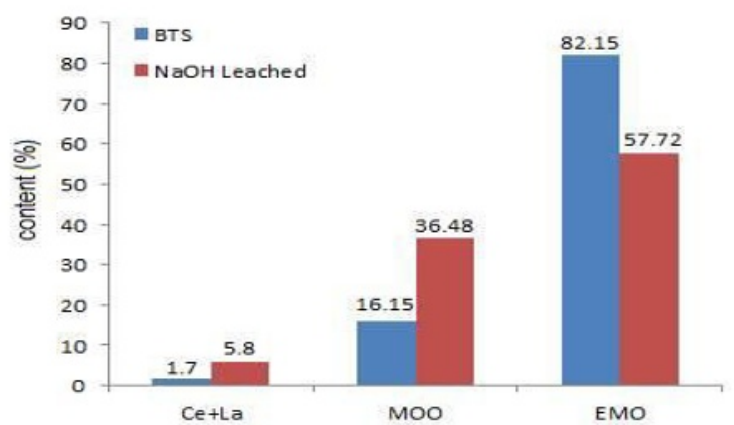

Fig. 2. The $\mathrm{Ce}+\mathrm{La}, \mathrm{MOO}$, and EMO contents ratio of BTS to $\mathrm{NaOH}-$ leached BTS-RQS.
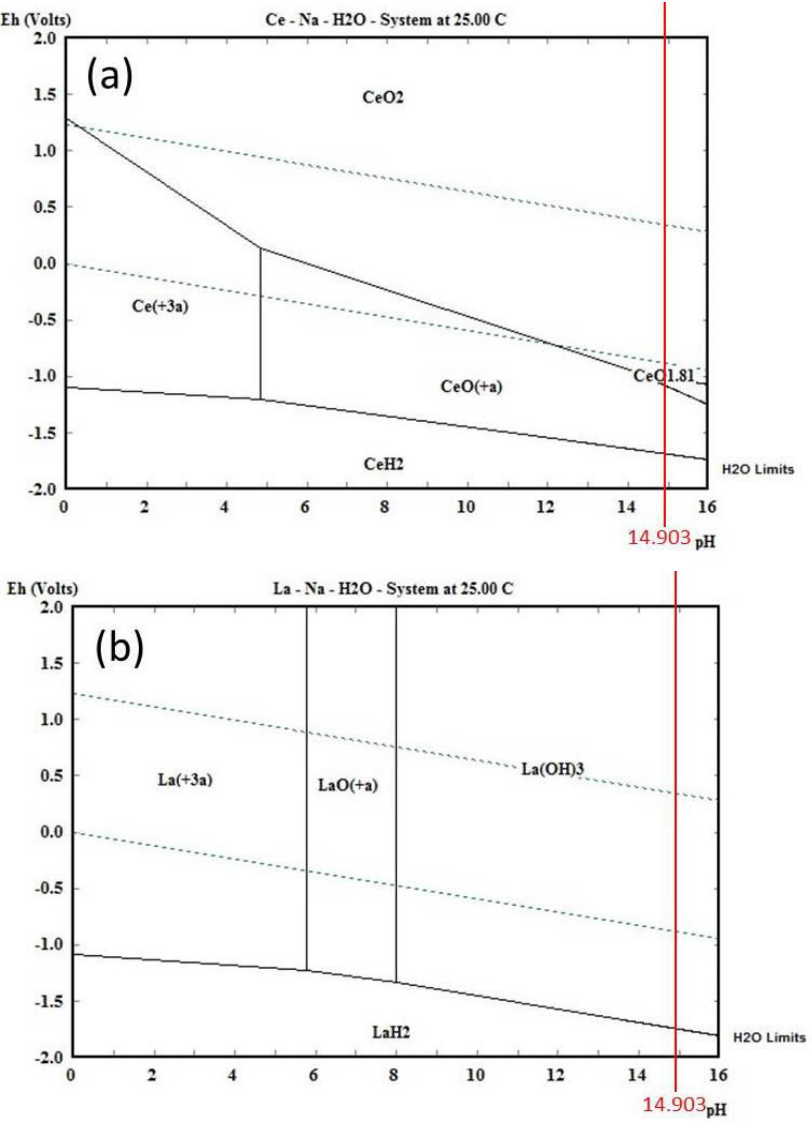

Fig. 3. The Pourbaix diagrams of dissolution in $\mathrm{NaOH}$ : (a) cerium and (b) lanthanum.

Table 4. The $\Delta \mathrm{G}$ of $\mathrm{MOO}$ dissolution in $\mathrm{NaOH}$.

\begin{tabular}{clc}
\hline No. & \multicolumn{1}{c}{ Reaction Equation } & $\Delta \mathbf{G}_{\mathbf{2 5}}{ }^{\circ}$ (kcal) \\
\hline 1. & $\begin{array}{l}\mathrm{SiO}_{2}+2 \mathrm{NaOH}=\mathrm{Na}_{2} \mathrm{SiO}_{3}+ \\
\mathrm{H}_{2} \mathrm{O}\end{array}$ & -21.228 \\
\hline 2. & $\begin{array}{l}6 \mathrm{TiO}_{2}+2 \mathrm{NaOH}=\mathrm{Na}_{2} \mathrm{Ti}_{6} \mathrm{O}_{13}+ \\
\mathrm{H}_{2} \mathrm{O}\end{array}$ & -23.582 \\
\hline 3. & $\begin{array}{l}\mathrm{Fe}_{2} \mathrm{O}_{3}+2 \mathrm{NaOH}=2 \mathrm{NaFeO}_{2}+ \\
\mathrm{H}_{2} \mathrm{O}\end{array}$ & -4.262 \\
\hline 4. & $\mathrm{CaO}+\mathrm{NaOH}=/$ & -8.165 \\
\hline 5. & $\begin{array}{l}\mathrm{Al}_{2} \mathrm{O}_{3}+2 \mathrm{NaOH}=2 \mathrm{NaAlO}_{2}+ \\
\mathrm{H}_{2} \mathrm{O}\end{array}$ & -5.954 \\
\hline 6. & $\begin{array}{l}\mathrm{ZrO} \mathrm{O}_{2}+\mathrm{NaOH}=\mathrm{Na}_{2} \mathrm{ZrO}_{3}+ \\
\mathrm{H}_{2} \mathrm{O}\end{array}$ & $\begin{array}{r}\text { Not found from } \\
\text { database }\end{array}$ \\
\hline 7. & $\begin{array}{l}\mathrm{SnO}_{2}+\mathrm{NaOH}=\mathrm{Na}_{2} \mathrm{SnO}_{3}+ \\
\mathrm{H}_{2} \mathrm{O}\end{array}$ &
\end{tabular}

\section{4. $\mathrm{HClO}_{4}$ Leaching of $\mathrm{NaOH}$-Leached Residues}

As shown on Fig.4 (a), after being leached with $\mathrm{HClO}_{4}$, $\mathrm{Ce}+$ la contents were relatively stable even though the concentration of $\mathrm{HClO}_{4}$ was raised. On the other hand, the results of AAS characterization of MOO: $\mathrm{Fe}$ and $\mathrm{Ce}$ show an increase in $\mathrm{Fe}$ and $\mathrm{Ca}$ contents. This phenomenon implies that, first, the solubility of $\mathrm{Fe}$ and $\mathrm{Ca}$ rises as the concentration of $\mathrm{HClO}_{4}$ is increased and, secondly, MOO contents in the residues decline, as shown on Fig. 4 (b).

For the analysis of $\mathrm{HClO}_{4}$ leaching, the $\mathrm{pH}$ of $\mathrm{HClO}_{4}$ was calculated first, as shown in Table 5. The evaluation of $\mathrm{Ce}$ and $\mathrm{La}$ at $\mathrm{pH}=0.097,0.4$, and 1 shows $\mathrm{Ce}$ in the form of $\mathrm{CeH}_{2}, \mathrm{CeCl}^{+\mathrm{a}}$, and $\mathrm{CeClO}_{4}{ }^{+2 \mathrm{a}}$, as shown on Fig.5 (a), while $\mathrm{La}$ in the form of $\mathrm{LaH}_{2}$, $\mathrm{LaCl}^{+2 \mathrm{a}}$, and $\mathrm{La}^{+3 \mathrm{a}}$, as shown on Fig. 5 (b). This implies that $\mathrm{Ce}$ and $\mathrm{La}$ are massively dissolved.

$\mathrm{HClO}_{4}$ leaching resulted in a decrease in all $\mathrm{MOO}$ contents in the residues, as shown on Fig.4 (b). This was signified by a rise in $\mathrm{Ca}$ and $\mathrm{Fe}$ contents in the filtrates, as shown in Table 6. This condition indicates that $\mathrm{HClO}_{4}$ leaching dissolves $\mathrm{Ca}$ and $\mathrm{Fe}$. In general, $\mathrm{HClO}_{4}$ leaching leads to the decrease in the contents of $\mathrm{Ce}+\mathrm{La}$ and MOO, but causes the rise in EMO contents, as shown on Fig. 6.

Table 5: The results of $\mathrm{pH}$ calculation of $\mathrm{HClO}_{4}$.

\begin{tabular}{cc}
\hline Concentration of $\mathrm{HClO}_{4}(\mathrm{M})$ & $\mathrm{pH}\left(\mathrm{pH}=-\log \mathrm{C}_{\mathrm{H}}{ }^{+}\right)$ \\
\hline 0.1 & 1 \\
\hline 0.4 & 0.4 \\
\hline 0.8 & 0.097 \\
\hline
\end{tabular}
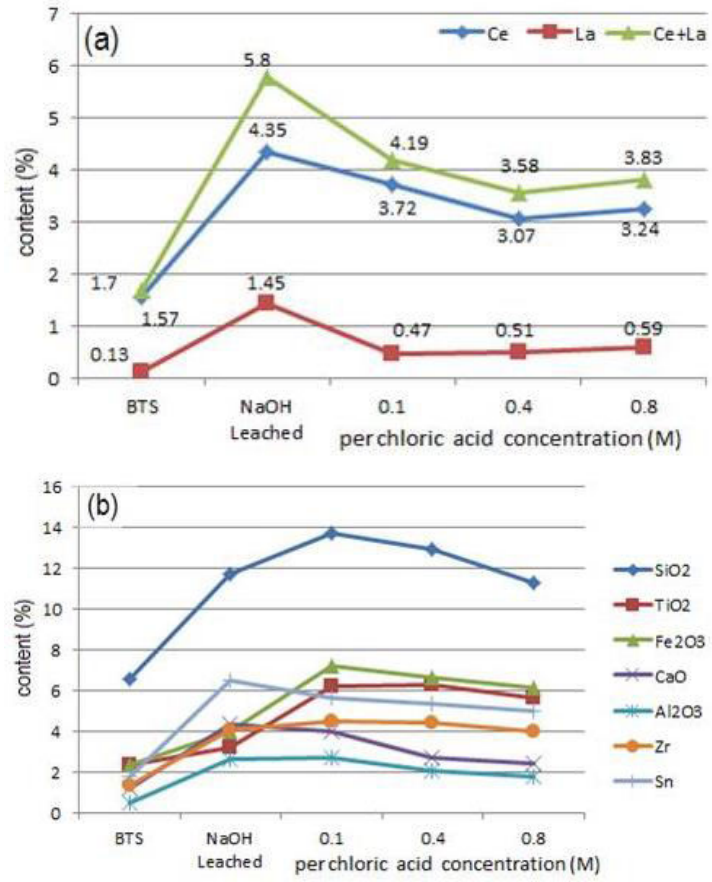

Fig. 4. The results of XRF characterization of BTS, the results of $\mathrm{NaOH}$ leaching, and the results of $\mathrm{HClO}_{4}$ leaching: (a) $\mathrm{Ce}$, $\mathrm{La}$, and $\mathrm{Ce}+\mathrm{La}$ and (b) $\mathrm{SiO}_{2}, \mathrm{TiO}_{2}, \mathrm{Fe}_{2} \mathrm{O}_{3}, \mathrm{CaO}, \mathrm{Al}_{2} \mathrm{O}_{3}, \mathrm{Zr}$, and $\mathrm{Sn}$ 


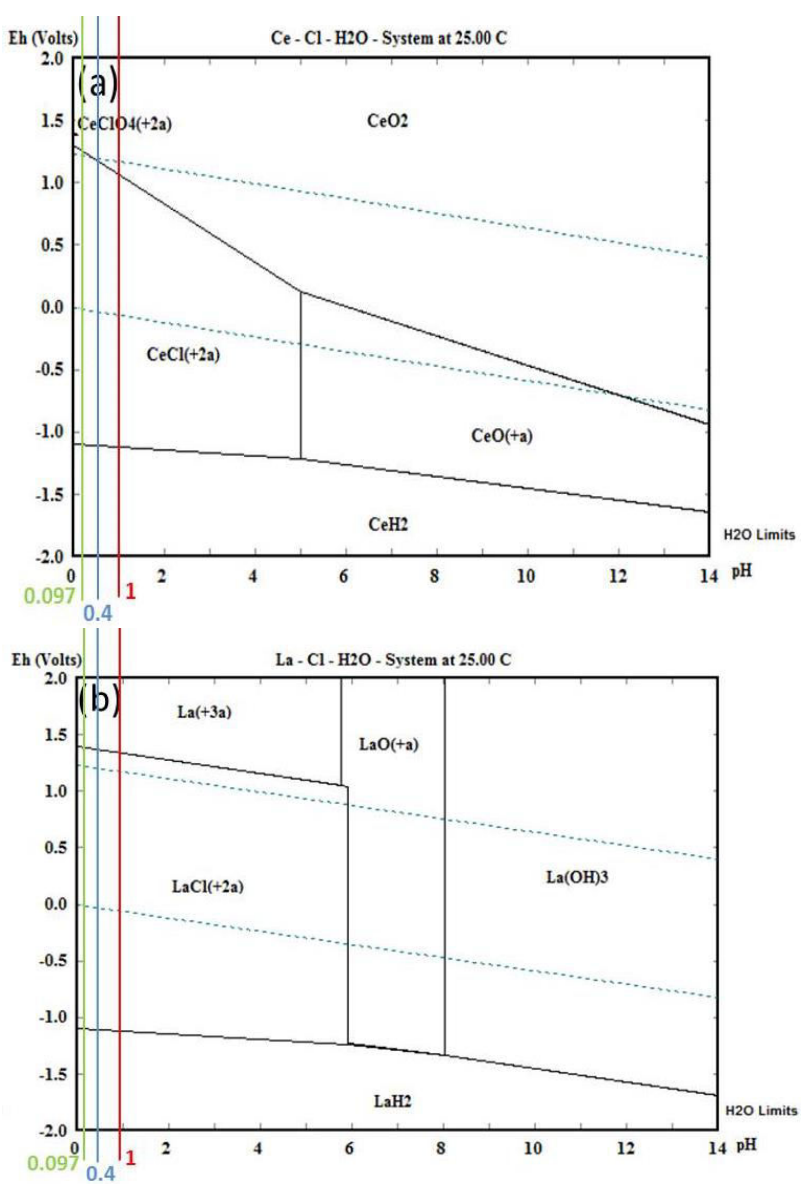

Fig.5. The Pourbaix diagrams of dissolution in $\mathrm{HClO}_{4}$ : (a) cerium and (b) lanthanum.

Table 6. The results of AAS characterization of $\mathrm{Ca}$ and $\mathrm{Fe}$ in the filtrates from $\mathrm{HClO}_{4}$ leaching

\begin{tabular}{ccc}
\hline \multirow{2}{*}{$\begin{array}{c}\text { concentration of per } \\
\text { chloric acid (M) }\end{array}$} & \multicolumn{2}{c}{ content ( ppm) } \\
\cline { 2 - 3 } & Calcium & Ferro \\
\hline 0.1 & $3,466.25$ & 82.33 \\
\hline 0.4 & $3,874.75$ & 626.9 \\
\hline 0.8 & $4,672.75$ & $1,281.6$ \\
\hline
\end{tabular}

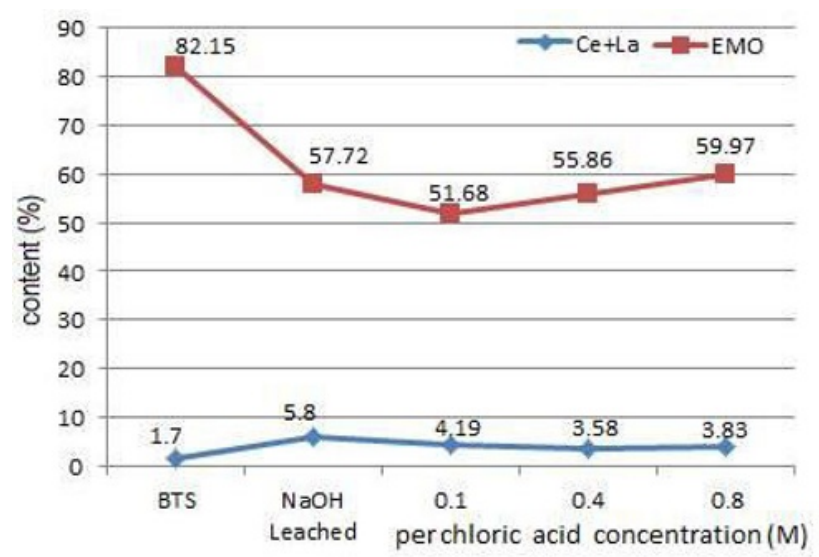

Fig. 6. The contents of $\mathrm{Ce}+\mathrm{La}$ and $\mathrm{EMO}$ as the concentration of $\mathrm{HClO}_{4}$ was raised

\section{Conclusions}

Processing BTS with roasting, water-quenching, and $\mathrm{NaOH}$ leaching followed by $\mathrm{HClO}_{4}$ to recover cerium and lanthanum, in summary, yields several results as follows:

1. Sieving BTS that has undergone $900^{\circ} \mathrm{C}$ roasting and water-quenching produces various particle sizes having different $\mathrm{Ce}+\mathrm{La}$ contents. The optimal $\mathrm{Ce}+\mathrm{La}$ contents are present in $-200+250$ mesh.

2. The analysis of $\mathrm{NaOH}$ dissolution in BTS shows an increase in $\mathrm{Ce}+\mathrm{La}$ contents due to two factors. First, cerium slightly dissolves in $\mathrm{NaOH}$ while lanthanum is insoluble in $\mathrm{NaOH}$ and, secondly, almost $+25 \%$ EMO dissolves in $\mathrm{NaOH}$.

3. The dissolution of $\mathrm{HClO}_{4}$ leads to a decrease in $\mathrm{Ce}+\mathrm{La}$ contents since $\mathrm{Ce}$ and $\mathrm{La}$ are largely soluble in $\mathrm{HClO}_{4}$ as well as MOO. However, the solubility of $\mathrm{Ce}+\mathrm{La}$ and $\mathrm{MOO}$ increases the contents of EMO.

To obtain the optimal contents of cerium and lanthanum, Bangka tin slag is processed by roasting $900^{\circ} \mathrm{C}$, water-quenching, and leaching of $\mathrm{NaOH}$, not $\mathrm{HClO}_{4}$.

This work was supported by the Directorate of Research and Community Engagement, Universitas Indonesia through 2018 PITTA Scheme.

\section{References}

1. Agulyonski A 2004 The Chemistry of Tantalum and Niobium Flouride Compounds (Amsterdam: Elsevier B.V.)

2. Konopka G, Zglinicki $\mathrm{K}$ and Marciniakmaliszewska B 2013 New potential source of rare earth elements.

3. Anggraini M 2016 Separation Process of Radioactive and Rare Earth Elements From Slag II of Tin Roasting (Master Thesis, Institut Teknologi Sepuluh Nopember)

4. Gaballah I, Allain E and Djona M 1997 Extraction of Tantalum and Niobium from Tin Slags by Chlorination and Carbochlorination Metall. Mater. Trans. 28

5. Ahmed M J K and Ahmaruzzaman M 2016 A review on potential usage of industrial waste materials for binding heavy metal ions from aqueous solutions J. Water Process Eng. 10 39-47

6. Gomes H I, Jones A, Rogerson M, Greenway G M, Lisbona D F, Burke I T and Mayes W M 2017 Removal and recovery of vanadium from alkaline steel slag leachates with anion exchange resins $J$. Environ. Manage. 187 384-92

7. Liu Z and Li H 2015 Metallurgical process for valuable elements recovery from red mud - A review Hydrometallurgy 155 29-43

8. Ayres R U, Peiró L T and Ayres R U 2013 
Material efficiency: rare and critical metals Philos. Trans. R. Soc. A 21

9. Peelman S, Sun Z H I, Sietsma J and Yang Y 2014 Leaching Of Rare Earth Elements: Past and Present 446-56

10. Lehmann B 2014 Economic geology of rare-earth element in 2014 : a global perspective

11. Permana S, Soedarsono J W, Rustandi A and et.al 2016 Other Oxides Pre-removed from Bangka Tin Slag to Produce a High Grade Tantalum and Niobium Oxides Concentrate IOP Conference Series: Materials Science and Engineering vol 12006p 10

12. S. Permana, J.W. Soedarsono, A. Rustandi, A. Maksum, K.S. Widana K T and M A 2018 The Enhancement of Uranium and Thorium in Bangka Tin Slag Atom Indones. 44 6-11

13. Allain E, Djona M and Gaballah I 1997 Kinetics of Chlorination and Carbochlorination of Pure Tantalum and Niobium Pentoxides Metall. Mater. Trans. B 28 223-33

14. Brocchi E A and Moura F J 2008 Chlorination Methods Applied to Recover Refractory Metals from Tin Slags Miner. Eng. 21 150-6

15. Gaballah I and Allain E 1994 Recycling of Strategic Metals from Industrial Slag by a Hydroand Pyrometallurgical Process Resour. Conserv. Recycl. 10 75-85

16. Subramanian C and Suri A K 1998 Recovery of Niobium and Tantalum from Low Grade Tin Slag A Hydrometallurgical Approach Environ. Waste Manag. 100-7

17. Meor Yusoff M.S. and Muslimin M 2007 Uranium and Thorium Analysis In Tin Slag by EDXRF $J$. Nucl. Relat. Technol. 4 177-80

18. Meor Yusoff M.S. and Muslimin M 2010 Quantitative Analysis of Uranium and Thorium in Local Zircon and Tin Slag by The EDXRF Technique J. Nucl. Relat. Technol. 7 21-8

19. Jun T, Jingqun Y, Ruan C, Guohua R, Mintao J and Kexian O 2010 Kinetics on leaching rare earth from the weathered crust elution-deposited rare earth ores with ammonium sulfate solution Hydrometallurgy 101 166-70

20. Xuewu L and Byrne R H 1997 Rare earth and yttrium phosphate solubilities in aqueous solution Geochim. Cosmochim. Acta 61 1625-33

21. Migdisov A A, Williams-jones A E and Wagner T 2009 An experimental study of the solubility and speciation of the Rare Earth Elements ( III ) in fluoride- and chloride-bearing aqueous solutions at temperatures up to $300{ }^{\circ} \mathrm{C}$ Geochim. Cosmochim. Acta 73 7087-109

22. Gao W C, Wen J K, Wu B and Shang H 2014 Extraction of niobium, yttrium, and cerium from a low-grade niobium-bearing ore by roasting (NH4)2SO4-Na2SO4-H2SO4system Rare Met. 33 754-60

23. Pepper R A, Couperthwaite S J and Millar G J 2016 Comprehensive examination of acid leaching behaviour of mineral phases from red mud: Recovery of Fe, Al, Ti, and Si Miner. Eng. 99 8-18
24. Saylor D M, Rohrer G S, Carter W C, Langer S A and Jr E R F 2001 Residual-Stress Predictions in Polycrystalline Alumina J. Am. Ceram. Soc. 54

25. Callister W D and Rethwisch D G 2014 Materials Science and Engineering, John Wiley \& Sons, Inc.

26. Soedarsono J W, Permana S, Hutauruk J K, Adhyputra R, Rustandi A, Maksum A, Widana K S, Trinopiawan K and Anggraini M 2018 Upgrading tantalum and niobium oxides content in Bangka tin slag with double leaching IOP Conf. Series : Materials Science and Engineering p 10 